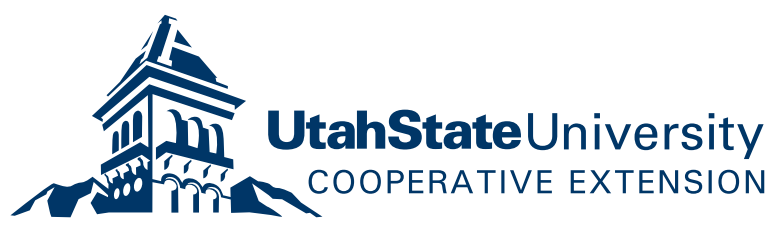

\title{
Agricultural Health and Safety
}

Fact Sheet AHS-09

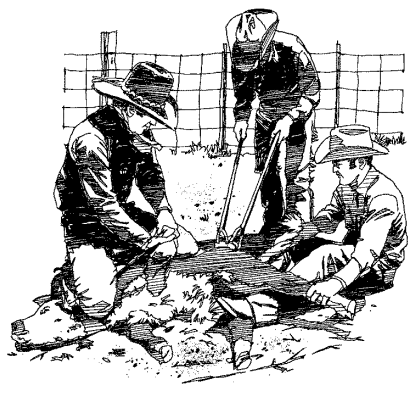

\section{Mental Health and Stress Management}

\author{
Jill Webster Ph.D., \\ Mark Gonzalez, Graduate Assistant \\ Agricultural Systems Technology and Education
}

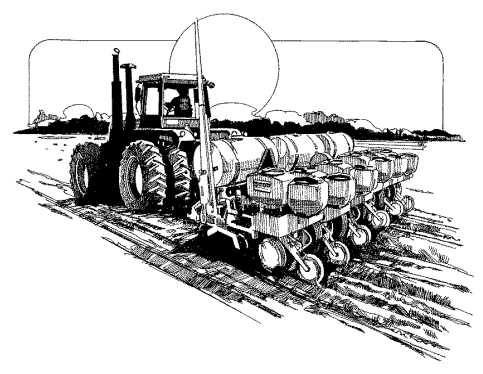

Farmers and ranchers experience many stress factors that are unique to their jobs and way of life. These stress factors are very difficult to cope with. These stress factors include: weather conditions, markets, time constraints, milk and commodity prices, crop and livestock disease, governmental regulations, high interest rates, high property taxes, foreclosure, bankruptcy, and competition. If these stress factors are allowed to build up, they have the potential to affect the mental health of the agriculturist and their family. To ensure mental health, it is important that farmers be aware of methods of stress reduction to help them cope with the pressures inherent within agriculture. Below are several stress reduction methods that when applied are all effective ways of reducing stress and improving mental health.

\section{Exercise}

Stress is the result of the "fight or flight" response. In today's world, it is important to have other ways of dealing with this energy rather than fighting or running away. Exercise is the most constructive and logical way to relieve this excess energy. Exercise clears the mind and puts the body in a more healthful state. It isn't necessary to spend hour after hour at the gym. An exercise program that breaks your daily routine will increase circulation, ease tension, and improve your mood. Suggested activities include: walking, jogging, swimming, dancing, skiing, aerobics, bicycling, and racquet sports. As a general rule, it is important to exercise three times a week for a minimum of 30 minutes each time. Choose a variety of activities that you enjoy to prevent exercise from being a burden.

\section{Caffeine}

In terms of inputs and results, one of the easiest and most effective methods of reducing stress is to reduce your daily intake of caffeine. Caffeine is a drug (stimulant) that is found in chocolate, cola drinks, coffee, and tea. Gradual weaning from caffeine over o period of two to three weeks will prevent resulting headaches. Caffeine remains in the body for many hours making it possible for the body to never cleanse itself or function caffeine-free before ingesting more caffeine. Reducing caffeine intake has many stress reducing benefits. These benefits include being more relaxed, sleeping better, being less jittery or nervous, and ironically having more energy.

\section{Humor}

Nothing can make life easier to deal with than laughter. Laughter reduces stress and 
relieves tension. Laughter is the best medicine money can buy. It is important to remember not to take life too seriously and to laugh at ourselves. When we view life from a humorous angle, it is difficult to focus on the things that cause stress in our lives. Here are some suggestions to increasing the humor in your life: 1) rent your favorite comedy video, 2 ) by a joke book and always have a good joke ready to tell, 3) call a friend who makes you laugh.

\section{Talk to Someone}

It is important to have a strong network of family and friends that can serve as a support system. Having someone who will listen and allow you to vent your problems is very valuable. Talking about problems and situations help to put them into perspective making it easier to deal with them. Talking to someone lightens the burden by providing someone who will share the load. Friends are very helpful whin going through difficult times. Regular conversation and participation in social groups and settings are effective forms of reducing stress and increasing mental health.

\section{Relation Techniques}

Stress is the automatic build up of tension and readiness that is a result of the "fight or flight" response. We can combat this build up through conscious relaxation techniques. There are several suggested techniques that anyone can try. First, slow and repetitive deep breathing exercises are very effective at reducing heart rate. Second, take mini-breaks that segment you day and give you an opportunity to clear your mind and refocus. Third, meditation also reduces stress. For a sustained period of time, 20 - 30 minutes, sit on a chair or lie on a bed and focus your thoughts on one thing such as an object, an image, a sound, even your own breathing. This removes problems and stressors from the mind and allows it the opportunity of resting. Fourth, get a massage. This works tension from affected muscles and increases range of muscular motion. Because relaxation is so effective, it should be done on days where exercise is not possible.

\section{Sleep}

People who are tired have a difficult time coping with stress. Here are three questions to you can ask yourself that will help you determine if you require more sleep.

1. Do you wake fully refreshed in the morning?

2. Do you have enough energy through the entire day?

3. Do you naturally wake before the alarm goes off?

If you are unable to answer these three questions positively, you should increase your sleep until you can answer all the questions with a "yes." A short "power nap" can also provide a midday boost.

Utah State University Extension does not discriminate on the basis of race, color, national origin, gender, religion, age, disability, political beliefs, sexual orientation, or marital or family status in employment or program delivery.

Issued in furtherance of Cooperative Extension work, Acts of May 8 and June 30, 1914, in cooperation with the U.S. Department of Agriculture, Robert L. Gilliland, Vice-President and Director, Cooperative Extension Service, Utah State University, Logan, Utah. (EP/04-01/DF) 